\title{
Evaluasi Penggunaan Antibiotik dengan Kartu Monitoring Antibiotik Gyssens
}

\author{
Irene Yuniar, Mulya Rahma Karyanti, Taralan Tambunan, Nanda Asyura Rizkyani \\ Departemen Ilmu Kesehatan Anak Fakultas Kedokteran Universitas Indonesia/RS Dr. Cipto \\ Mangunkusumo, Jakarta
}

\begin{abstract}
Latar belakang. Masalah infeksi yang sering ditemui di ICU anak, disebabkan berbagai pemakaian antibiotik. Peningkatan penggunaan antibiotik diikuti dengan risiko penurunan kepekaannya sehingga perlu pengendalian pemakaiannya.

Tujuan. Evaluasi penggunaan antibiotik secara kualitatif di Pediatric Intensive Care Unit (PICU) dengan menggunakan alur Gyssens.

Metode. Uji potong lintang retrospektif dengan mengevaluasi penggunaan antibiotik melalui kartu monitoring serta dilakukan analisis dengan alur Gyssens di PICU dari tanggal 10 Februari 2012 sampai 31 Juli 2012.

Hasil. Selama kurun waktu 5 bulan, 233 pasien dirawat di ICU Anak RS. Cipto Mangunkusumo Jakarta dan 45 (19,3\%) pasien menggunakan antibiotik. Penggunaan antibiotik terbanyak pada kelompok umur 1 bulan sampai 1 tahun. Pada 83 penggunaan antibiotik, 64 antibiotik dipakai sebagai terapi empiris, 11 definitif, dan 8 profilaksis. Lima antibiotik terbanyak yang digunakan adalah sefotaksim, amikasin, piperasilin tazobaktam, meropenem, dan metronidazol. Penggunaan antibiotik yang tepat (alur Gyssens kategori I) didapatkan pada 53\% pasien yang dirawat di PICU.

Kesimpulan. Penggunaan antibiotik dengan justifikasi yang tepat dapat diterapkan dan diharapkan dapat menurunkan resistensi antibiotik, mengurangi beban biaya pasien serta meningkatkan kualitas pelayanan pasien di ICU Anak. Selain itu, diperlukan pelatihan pengambilan spesimen yang tepat secara berkala, serta dihimbau untuk mengisi formulir antibiotik secara tepat dan benar.
\end{abstract}

Sari Pediatri 2013;14(6):384-90.

Kata kunci: antibiotik, alur Gyssens, terapi empiris

\footnotetext{
Alamat korespondensi:

Dr. Irene Yuniar, Sp.A. Departemen Ilmu Kesehatan Anak FKUI/RS Dr.

Cipto Mangunkusumo, Jakarta. E-mail: irene.tambunan@yahoo.co.id
}

nfeksi merupakan masalah tersering ditemui pada pasien yang dirawat di ruang perawatan intensif (intensive care unit/ICU), dan antibiotik sering digunakan untuk mengatasi masalah 
ini. ${ }^{1}$ Antibiotik dapat dipakai sebagai terapi empiris, definitif, maupun profilaksis pasien-pasien yang dirawat di ICU untuk pasien yang menggunakan ventilator, pasien dengan sistem imunitas yang rendah dan sebagainya. Pemakaian antibiotik yang cukup tinggi berhubungan erat dengan peningkatan masalah resistensi antibiotik. ${ }^{2}$ Oleh sebab itu, penggunaan antibiotik di ICU harus berdasarkan justifikasi yang tepat sehingga menurunkan resistensi antibiotik yang beberapa tahun terakhir menjadi sorotan penting di dunia. ${ }^{1,3}$ Berdasarkan surviving sepsis campaign tahun 2008 disebutkan bahwa antibiotik empiris pada pasien sepsis direkomendasikan untuk diberikan segera setelah diagnosis klinis sepsis ditegakkan. ${ }^{4}$ Evaluasi penggunaan antibiotik empiris secara berkala diperlukan dan disesuaikan dengan pola bakteri. ${ }_{1,5}$ Suatu studi analisis multivariat mengemukakan bahwa mortalitas pasien ICU ditentukan oleh beratnya penyakit (menggunakan skor APACHE/ acute physiology and chronic health evaluation), disfungsi multiorgan, penggunaan vasopresor serta ketidaktepatan penggunaan antitiotik. Ketidaktepatan penggunaan antibiotik akan meningkatkan mortalitas sebesar 4,22 kali. ${ }^{6}$

Sampai dengan tahun 2009, Rumah Sakit Cipto Mangunkusumo (RSCM) tidak mempunyai data yang lengkap dan akurat mengenai pemakaian antibiotik. Pada bulan Juli 2009, dibentuklah suatu tim Program Pengendalian Resistensi Antibiotik (PPRA) RSCM yang di dalamnya terdapat 4 pilar, yaitu Tim Mikrobiologi Klinik, Tim Farmasi Terapi, Komite Pengendalian Infeksi Rumah Sakit (PPIRS), dan Farmakologi Klinik. ${ }^{7}$ Berdasarkan survei yang dilakukan oleh tim Program Pengendalian Infeksi Antibiotik (PPRA) Departemen Ilmu Kesehatan Anak pada bulan Juni-November 2011, didapatkan bahwa penggunaan antibiotik di unit perawatan intensif anak (Pediatric Intensive Care Unit/PICU) cukup tinggi.

Tim PPRA RSCM kemudian menyusun kartu monitoring antibiotik yang digunakan secara resmi di Departemen Ilmu Kesehatan Anak pada tanggal 10 Februari 2012. Data dari pengisian kartu monitoring dipakai untuk menilai setiap antibiotik yang digunakan baik secara kualitatif (dengan menggunakan alur Gyssens) ${ }^{8}$ maupun kuantitatif. Tujuan penelitian ini adalah melakukan penilaian kualitatif terhadap penggunaan antibiotik dengan menggunakan alur Gyssens di PICU RSCM.

\section{Metode}

Penelitian potong lintang retrospektif dengan mengevaluasi penggunaan antibiotik melalui kartu monitoring serta dilakukan analisis dengan alur Gyssens. Evaluasi dilakukan selama 5 bulan penggunaan kartu, yaitu dari tanggal 10 Februari 2012 sampai 31 Juli 2012. Kriteria inklusi adalah pasien yang menggunakan antibiotic, baik sebagai terapi empiris, definitive, atau profilaksis yang masuk ke PICU dalam kurun waktu penelitian. Terapi empiris merupakan terapi antibiotik pada infeksi sebelum kuman penyebab diketahui, terapi definitif diberikan jika kuman penyebab sudah diketahui, terapi profilaksis diberikan untuk mencegah kemungkinan terjadinya infeksi. Obat selain antibiotik tidak dicatat pada kartu ini. Pasien yang sebelumnya mendapat perawatan $>48$ jam di luar PICU dianggap sebagai pasien yang pernah rawat sebelumnya. Pasien yang sudah pindah dari PICU kemudian masuk kembali ke PICU, dalam waktu >48 jam dianggap sebagai pasien baru di PICU.

Diagnosis utama ada atau tidaknya infeksi bakterial, fungsi ginjal, dan hati dicatat untuk menilai apakah pemakaian antibiotik sudah sesuai indikasi. Dosis antibiotik yang digunakan berdasarkan buku Drug doses yang ditulis oleh Frank Shann. ${ }^{9}$ Pasien

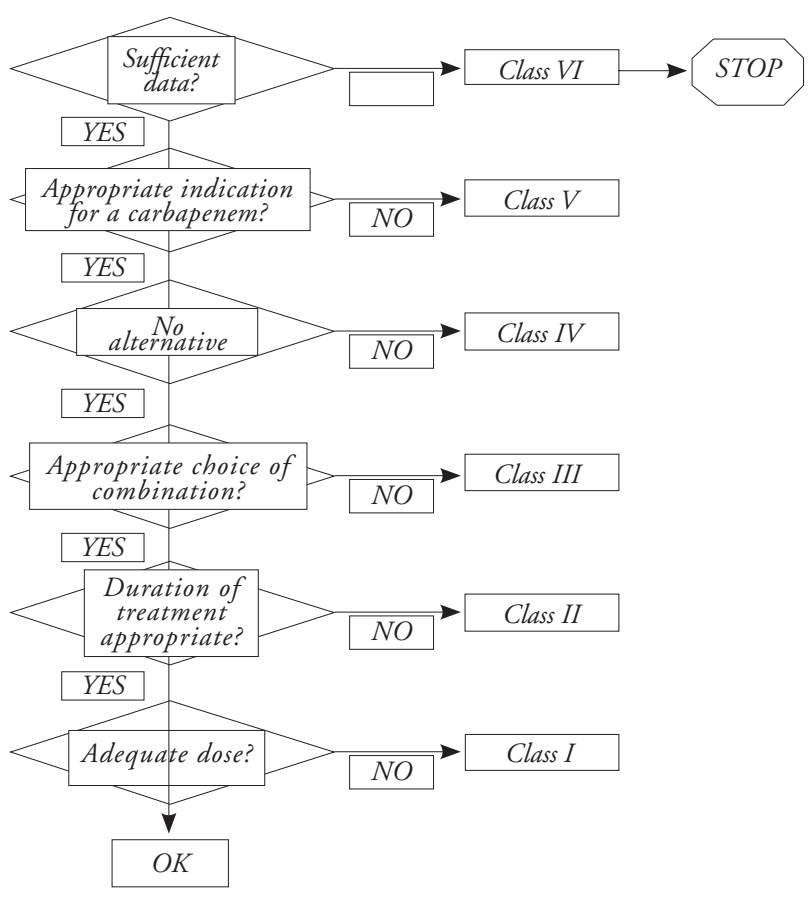

Gambar 1. Alur Gyssens ${ }^{8}$ 
yang mengalami penurunan fungsi ginjal dilakukan penyesuaian dosis antibiotic, ${ }^{10,11}$ sedangkan pasien yang mengalami penurunan fungsi hati tidak dilakukan penyesuaian dosis antibiotik. ${ }^{13,14}$ Kriteria sepsis yang dipakai berdasarkan surviving sepsis campaign 2009 dengan definisi sepsis adalah Systemic inflammatory response syndrome (SIRS) dengan atau tanpa hasil kultur yang positif secara mikrobiologis. ${ }^{4}$ Antibiotik diberikan oleh tiga orang Dokter Penanggujawab Pasien (DPJP) PICU berdasarkan klinis pasien, fokus infeksi, panduan pelayanan medis, ${ }^{15}$ dan buku formularium Rumah Sakit Umum Pusat Nasional Cipto Mangunkusumo. ${ }^{16}$

Setiap pemakaian antibiotik dicatat tujuan pemberian antibiotik (empiris, definitif, profilaksis), jenis, dosis, interval pemberian, lama pemberian, reaksi alergi antibiotik apabila ada serta hasil akhir pengobatan dengan antibiotik tersebut. Dosis pasien disesuaikan apabila terdapat gangguan fungsi ginjal tetapi pada gangguan fungsi hati dosis obat tetap diberikan seperti biasa, dan dilakukan pemantauan ketat fungsi hati yang dipandu oleh Supervisor Divisi Gastrohepatologi. Selain itu, juga dicatat apakah dilakukan kultur sebelumnya baik kultur darah, urin, sputum, cairan serebrospinal dan feses. Evaluasi dengan alur Gyssens (Gambar 1) dilakukan dengan cara menggolongkan setiap antibiotik menjadi 6 kategori, yaitu kategori VI (penggunaan tidak tepat karena catatan rekam medik tidak lengkap untuk dievaluasi), kategori $\mathrm{V}$ (penggunaan tidak tepat karena tidak ada indikasi), kategori IVa (penggunaan tidak tepat karena ada antibiotik lain yang lebih

Tabel 1. Karakteristik subyek penelitian

\begin{tabular}{lcc}
\hline Karakteristik & Jumlah $(\mathrm{n})$ & $\%$ \\
\hline Kelompok umur & 5 & 11,1 \\
< 1 bulan & 21 & 46,7 \\
1 bulan-1 tahun & 13 & 28,9 \\
$>1-5$ tahun & 5 & 11,1 \\
6-12 tahun & 1 & 2,2 \\
13-18 tahun & & \\
Jenis kelamin & 18 & 40 \\
Laki-laki & 27 & 60 \\
Perempuan & & \\
Jenis kasus & 19 & 42,2 \\
Bedah & 26 & 57,8 \\
Non bedah & & \\
Status gizi & 8 & 17,8 \\
Buruk & 9 & 20,0 \\
Kurang & 25 & 55,6 \\
Normal & 3 & 6,7 \\
Overweight & &
\end{tabular}

efektif), kategori IVb (penggunaan tidak tepat karena ada antibiotik lain yang lebih aman), kategori IVc (penggunaan tidak tepat karena ada antibiotik lain yang lebih murah), kategori IVd (penggunaan tidak tepat karena ada antibiotik lain yang spektrumnya lebih spesifik), kategori IIIa (penggunaan tidak tepat karena terlalu lama), kategori IIIb (penggunaan tidak tepat karena terlalu singkat), kategori IIa (penggunaan tidak tepat dosis pemberian), kategori IIb (penggunaan tidak tepat interval pemberian), kategori IIc (penggunaan tidak tepat cara/rute pemberian) dan kategori I penggunaan antibiotik tepat. Hasil akhir pemakaian antibiotik juga dicatat. Pasien dinyatakan sembuh apabila dapat keluar dari ICU Anak dalam keadaan stabil dan dapat menjalani perawatan di ruang rawat biasa.

\section{Hasil}

Selama kurun waktu 5 bulan pasien yang dirawat di ICU Anak sebanyak 233 pasien dan yang menggunakan antibiotik sebanyak 45 pasien (19,3\%). Sebaran data karakteristik pasien dapat dilihat pada tabel 1.

Penggunaan antibiotik terbanyak pada kelompok umur 1 bulan sampai 1 tahun. Kasus bedah yang diduga disertai dengan infeksi bakteri terdapat pada 19 dari 45 pasien ( $42,2 \%$ pasien) yang mendapat antibiotik. Pasien yang datang ke PICU sebagian besar mempunyai lebih dari satu diagnosis karena sudah mengalami komplikasi. Dari 45 pasien yang menggunakan antibiotik didapatkan 63 diagnosis dan yang terbanyak adalah sepsis $(40 \%)$, diikuti dengan kasus bedah saluran cerna (19\%), gangguan susunan saraf pusat $(17,2 \%)$, pneumonia $(12,7 \%)$ dan gangguan ginjal $(11,1 \%)$. Dari 45 pasien dengan 63 diagnosis didapatkan pemakaian antibiotik sebanyak 83 penggunaan antibiotik. Terdapat 8 pasien mendapatkan kombinasi 2 antibiotik secara bersamaan dan 2 pasien yang mendapatkan kombinasi 3 antibiotik pada saat bersamaan.

Pada 83 penggunaan antibiotik, 64 antibiotik dipakai sebagai terapi empiris, 11 definitif dan 8 profilaksis. Antibiotik empiris diberikan pada 31 pasien sepsis dan 33 pasien yang tidak sepsis, antibiotik definitif diberikan pada 8 pasien sepsis dan 3 pasien tidak sepsis. Semua antibiotik profilaksis diberikan pada pasien tidak sepsis. Grafik pemberian antibiotik berdasarkan ada tidaknya sepsis tertera pada Gambar 2. 
Tabel 2. Sebaran antibiotik yang digunakan

\begin{tabular}{lcc}
\hline Antibiotik yang digunakan & Jumlah (n) & $\%$ \\
\hline Beta laktam & & \\
$\quad$ Penisilin & 2 & 2,42 \\
Ampisilin & 2 & 2,42 \\
Ampisilin sulbaktam & 1 & 1,21 \\
Amoksisilin klavulanat & 10 & 12,10 \\
$\quad$ Piperasilin tazobaktam & & \\
Sefalosporin & 25 & 30,01 \\
$\quad$ Sefotaksim & 1 & 1,21 \\
$\quad$ Sefaleksin & 1 & 1,21 \\
$\quad$ Sefepim & 4 & 4,82 \\
$\quad$ Seftazidim & 3 & 3,61 \\
Seftriakson & & \\
Karbapenem & 8 & 9,64 \\
$\quad$ Meropenem & 5 & 6,02 \\
$\quad$ Metronodazol & 2 & 2,42 \\
Kloramfenikol & & \\
Aminoglikosid & 12 & 14,46 \\
$\quad$ Amikasin & 1 & 1,21 \\
Gentamisin & & \\
Glikopeptida & 2 & 2,42 \\
Vankomisin & 3 & 3,61 \\
Kuinolon & & 1,21 \\
Levofloksasin & & \\
Fosfomisin & & \\
\hline Jumlah & & \\
\hline
\end{tabular}

Tabel 3. Sebaran antibiotik berdasarkan terapi empiris, definitif dan profilaksis

\begin{tabular}{lccc}
\hline & Empiris & Definitif & $\begin{array}{c}\text { Profilaksis } \\
\text { Medis }\end{array}$ \\
\hline Amikasin & 10 & 2 & 0 \\
Ampisilin & 2 & 0 & 0 \\
Ampisilin sulbaktam & 1 & 1 & 0 \\
Amoksisilin klavulanat & 1 & 0 & 0 \\
Meropenem & 7 & 1 & 0 \\
Metronidazol & 5 & 0 & 0 \\
Piperasilin tazobaktam & 10 & 0 & 0 \\
Sefaleksin & 1 & 0 & 0 \\
Sefepim & 1 & 0 & 0 \\
Sefotaksim & 17 & 0 & 8 \\
Seftazidim & 4 & 0 & 0 \\
Seftriakson & 3 & 0 & 0 \\
Fosfomisin & 0 & 1 & 0 \\
Kloramfenikol & 2 & 0 & 0 \\
Levofloksasin & 0 & 3 & 0 \\
Vankomisin & 0 & 2 & 0 \\
Gentamisin & 0 & 1 & 0 \\
\hline Jumlah & 64 & 11 & 8 \\
\hline
\end{tabular}

Sebaran antibiotik yang digunakan tertera pada Tabel 2 .

Lima antibiotik terbanyak yang digunakan adalah sefotaksim, amikasin, piperasilin tazobaktam, meropenem dan metronidazol. Sebaran antibiotik yang digunakan berdasarkan terapi empiris, definitif dan profilaksis tertera pada Tabel 3.

Penilaian kualitatif antibiotik berdasarkan alur Gyssens dilakukan pada semua antibiotik yang diberikan di PICU. Hasil penilaian antibiotik secara kualitatif berdasarkan alur Gyssens tertera pada Tabel 4.

Penggunaan antibiotik yang tepat (alur Gyssens kategori I) didapatkan pada 53\% pasien yang dirawat di PICU. Penggunaan antibiotik dengan tepat (termasuk kategori I alur Gyssens) pada 5 pemakaian antibiotik terbanyak berturut-turut adalah sefotaksim 17 dari 25 pemakaian (68\%), amikasin 2 dari 12 pemakaian (16\%), piperasilin tazobaktam 6 dari 10 pemakaian (60\%), meropenem 4 dari 8 pemakaian (50\%) dan metronidazol 1 dari 5 pemakaian (20\%).

Pemeriksaan biakan dan uji kepekaan dilakukan pada 44 dari 64 penggunaan antibiotik empiris $(68,7 \%)$,

Tabel 4. Sebaran antibiotik berdasarkan alur Gyssens

\begin{tabular}{lll}
\hline Kategori Gyssens & Jumlah (n) & $\%$ \\
\hline I & 44 & 53 \\
IIa & 20 & 24 \\
IIb & 10 & 12 \\
IIIa & 4 & 4,82 \\
IIIb & 1 & 1,26 \\
IVa & 0 & 0 \\
IVb & 0 & 0 \\
IVc & 1 & 1,26 \\
IVd & 2 & 2,40 \\
V & 1 & 1,26 \\
VI & 0 & 0 \\
\hline & 83 & 100 \\
\hline
\end{tabular}

Tabel 5. Kesesuaian terapi empiris dengan hasil biakan dan uji kepekaan $(n=33)$

\begin{tabular}{lccc}
\hline \multirow{2}{*}{ Spesimen } & \multicolumn{3}{c}{ Terapi empiris } \\
\cline { 2 - 4 } & Sesuai & Tidak sesuai & Jumlah (n) \\
\hline Darah & 2 & 7 & 9 \\
Urin & 8 & 8 & 16 \\
Sputum & 1 & 4 & 5 \\
Tinja & 0 & 2 & 2 \\
Cairan CSS & 0 & 1 & 1 \\
\hline
\end{tabular}


Tabel 6. Sebaran spesimen dan hasil biakan tumbuh dan tidak tumbuh

\begin{tabular}{lcccc}
\hline \multirow{2}{*}{ Jenis spesimen } & \multirow{2}{*}{ Jumlah isolat } & \multicolumn{2}{c}{ Hasil biakan } & \multirow{2}{*}{ Persentase } \\
\cline { 3 - 4 } & & Tumbuh & Tidak tumbuh & 81,8 \\
Darah & 55 & 10 & 45 & 11,1 \\
Sputum & 9 & 8 & 1 & 24,3 \\
Urin & 37 & 28 & 9 & 0 \\
Tinja & 4 & 4 & 0 & 0 \\
Cairan serebrospinal & 7 & 7 & 0 & 0 \\
\hline
\end{tabular}

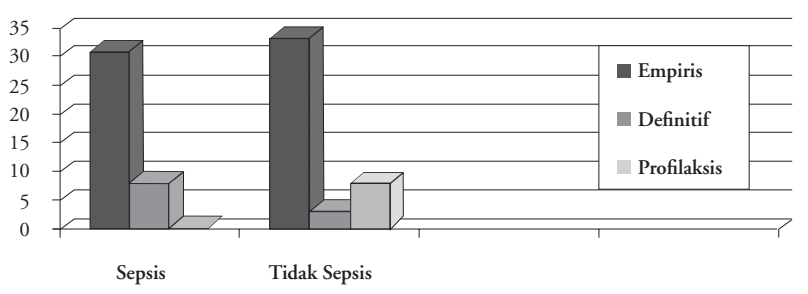

Gambar 2. Tujuan pemberian antibiotik berdasarkan adanya sepsis atau tidak

sisanya tidak dilakukan biakan. Dari 44 pemeriksaan biakan ini didapatkan 11 antibiotik dengan biakan sensitif (25\%), 22 antibiotik biakan resisten (50\%), dan 11 antibiotik biakan steril (25\%). Kesesuaian terapi empiris dengan 33 hasil biakan (baik sensitif dan resisten) dan uji kepekaannya tertera pada Tabel 5 .

Seluruh spesimen dan hasil biakan tumbuh dan tidak tumbuh tertera pada Tabel 6 .

\section{Pembahasan}

Angka kejadian infeksi di ruang rawat intensif masih cukup tinggi. Antibiotik digunakan secara luas di ruang rawat intensif, bahkan dapat mencapai 10 kali penggunaan di ruang rawat biasa. ${ }^{1}$ Resistensi terhadap berbagai jenis antibiotik juga sering terjadi. Penggunaan antibiotik yang meningkat mengakitbatkan masalah resistensi yang meningkat pula. Resistensi antibiotik akan menimbulkan masalah klinis serta biaya perawatan pasien yang meningkat sampai 100 kali lipat. Hal tersebut tidak menguntungkan terutama bagi negara berkembang. ${ }^{2}$ Oleh sebab itu, perlu adanya surveilans penggunaan antibiotik secara berkala di ruang rawat intensif agar penggunaan antibiotik dengan justifikasi yang tepat dapat tercapai dan mengurangi resistensi antibiotik. ${ }^{5}$ Di dunia, sampai saat ini, sangat sulit untuk mengumpulkan data mengenai penggunaan antibiotik di ruang rawat intensif. Oleh sebab itu, tim PPRA RSCM mengeluarkan kartu monitoring penggunaan antibiotik yang memudahkan evaluasi penggunaan antibiotik di rumah sakit.

Dari 83 penggunaan antibiotik, 39 antibiotik (47\%) diberikan pada 18 pasien sepsis yang 31 antibiotik di antaranya $(79,5 \%)$ dipakai sebagai terapi empiris. Hal tersebut sesuai dengan kriteria sepsis yang menyebutkan bahwa sepsis adalah SIRS yang dicurigai atau terbukti infeksi. Jadi meskipun belum terdapat bukti hasil kultur, antibiotik dapat diberikan secara empiris apabila SIRS sudah muncul.

Penggunaan antibiotik golongan glikopeptida seperti vankomisin dan golongan kuinolon seperti levofloksasin serta golongan karbapenem seperti meropenem harus dibatasi pada anak. Penggunaan jenis antibiotik ini harus secara bijaksana dengan mempertimbangkan untung-rugi penggunaan obat tersebut. Pada penelitian kami, meropenem dipakai sebagai terapi empiris pada tujuh kasus dengan mempertimbangkan klinis anak sepsis berat disetai disfungsi multiorgan. Tidak ada pemakaian antibiotik vankomisin dan levofloksasin sebagai terapi empiris. Semua pemakaian vankomisin dan levofloksasin diberikan sesuai hasil biakan dan uji kepekaannya.

Penilaian secara kualitatif dilakukan dengan alur Gyssens pada 83 antibiotik yang digunakan dengan hasil hanya 44 dari 83 antibiotik (53\%) yang masuk kategori I atau tepat dalam penggunaan antibiotik. Hal tersebut dapat disebabkan oleh berbagai faktor di antaranya dalam penghitungan dosis antibiotik pada pasien dengan penurunan fungsi ginjal tidak dilakukan penyesuaian, farmakodinamik dan farmakokinetik kurang tepat, pemakaian antibiotik yang cukup lama padahal minimal inhibition concentration (MIC) antibiotik sudah terlampaui sedangkan gejala klinis masih menunjukkan tanda SIRS dan diperlukan penggantian antibiotik segera.

Dari 64 antibiotik yang digunakan secara empiris, 20 penggunaan $(31,2 \%)$ tidak dilakukan kultur 
sebelumnya. Dalam Standar Prosedur Operasional (SPO) dan Instruksi Kerja (IK) yang dibuat oleh Tim PPRA memuat pengambilan biakan darah sebelum diberikan antibiotik. Biakan darah anaerob sebelum pemberian metronidazol tidak pernah dilakukan. Sebaiknya setiap Dokter Penanggung Jawab Pelayanan Pasien (DPJP) melakukan biakan spesimen sebelum menggunakan antibiotik sesuai SPO yang berlaku. Murthy $\mathrm{dkk}^{5}$ menyatakan bahwa setiap kuman mempunyai karakteristik masing-masing. Oleh sebab itu, penting untuk mengidentifikasikan kuman penyebab infeksi.

Berbeda dengan hasil yang didapatkan pada peta kuman RSCM yang dilakukan oleh Divisi Infeksi Departemen Patologi Klinik FKUI RSCM bulan Juli-Desember $2011^{17}$ yang menyatakan bahwa dari spesimen darah kultur tidak tumbuh sebesar $77,66 \%$, pada penelitian kami sebesar $81,8 \%$. Hal tersebut ${ }^{5}$ terjadi karena waktu pengambilan spesimen darah mungkin tidak tepat. Sebaiknya pengambilan spesimen darah dilakukan segera setelah terjadi demam dan tidak ditunda karena tingkat bakteremia dalam darah akan segera turun segera setelah puncak demam tercapai. Selain itu, jumlah volume spesimen darah yang diperlukan untuk biakan darah cukup banyak dan diperlukan dua spesimen darah dari dua tempat yang berbeda pada waktu bersamaan untuk menghindari kemungkinan kontaminan pada pemeriksaan darah. Namun, hal ini sering menimbulkan kontroversi pada perawatan anak, terutama anak dengan sakit kritis yang dirawat di ICU, serta membutuhkan biaya yang cukup besar. Pengambilan spesimen darah dalam jumlah banyak membuat anak jatuh pada keadaan anemia sehingga diperlukan transfusi sel darah merah untuk menggantikan volume darah yang diambil untuk pemeriksaan biakan.

Hasil biakan sputum tidak tumbuh pada penelitian didapatkan 1 dari 9 biakan (11,13\%), sedangkan berdasarkan peta kuman RSCM tahun $2011^{17}$ biakan sputum tidak tumbuh pada 14 dari 2367 (0,59\%). Pengambilan spesimen sputum pada pasien yang dirawat di ICU Anak dengan menggunakan selang penghisap (suction catheter) melalui selang endotrakeal (Endotracheal Tube/ETT) sehingga sulit mendapatkan jumlah spesimen yang cukup. Pada pasien anak yang sadarpun sulit untuk didapatkan jumlah sputum yang memadai karena anak sering belum dapat mengeluarkan sputum dengan baik. Selain dari jumlah spesimen yang tidak memadai, cara pengiriman spesimen sering belum memenuhi kriteria. Sebaiknya sputum dikirim dalam waktu 30 menit (selambat-lambatnya 2 jam) setelah sputum dikeluarkan dan sebaiknya sputum dikirim dalam kondisi yang dingin, tidak pada suhu kamar. Namun di lapangan, pengirimin ini sering terlambat.

Berdasarkan peta kuman RSCM tahun 2011, ${ }^{17}$ spesimen urin tidak tumbuh pada 486 dari 2709 $(17,94 \%)$ biakan, sedangkan pada penelitian kami didapatkan 9 dari 37 (24,3\%) biakan. Cara pengambilan spesimen, waktu, dan media transport sering menyebabkan hasil kultur dianggap tidak bermakna $\left(<10^{5}\right.$ koloni kuman/mL urin). Pada kultur tinja tidak pernah didapatkan hasil tidak tumbuh, tetapi merupakan flora normal saluran cerna yang sebenarnya tidak memerlukan terapi antibiotik.

Tigapuluh lima dari 64 pemakaian antibiotik empiris mempunyai hasil kultur positif. Dua belas dari 35 pemakaian antibiotik $(34,3 \%)$ sensitif terhadap antibiotik empiris yang dipilih, sedangkan sisanya $(65,7 \%)$ resisten terhadap antibiotik tersebut. Kesesuaian pilihan antibiotik empiris dengan hasil biakan untuk menilai ketepatan penggunaan antibiotik empiris sangat rendah. Untuk mengatasi masalah resistensi antibiotik, beberapa tahun terakhir dilakukan metode rotasi antibiotik yang digunakan. Raymon $\mathrm{dkk}^{18}$ melakukan penelitian pada pasien VAP dengan hasil pasien yang dilakukan rotasi antibiotik mortalitasnya menurun dari 33,8\% menjadi 18,6\% (dengan $\mathrm{p}=0,04$ ). Hal tersebut patut mendapat perhatian dari pihak terkait dalam penyusunan panduan pelayanan medis. Perlu adanya revisi Panduan Penggunaan Antibiotik (PPAB) di ICU Anak dengan memilih antibiotik yang diperkirakan masih sensitif. Sebagai kesimpulan, penggunaan antibiotik dengan justifikasi yang tepat dapat diterapkan dan diharapkan dapat menurunkan resistensi antibiotik, mengurangi beban biaya pasien, dan meningkatkan kualitas pelayanan pasien di ICU Anak. Selain itu, diperlukan pelatihan pengambilan spesimen yang tepat secara berkala serta dihimbau untuk mengisi formulir antibiotik secara tepat dan benar.

\section{Daftar pustaka}

1. Malacarne P, Rossi C, Bertolini G. Antibiotic usage in intensive care units: a pharmaco- epidemiological multicentre study. Diunduh dari: www.ncbi.nlm.nih.gov/ 
pubmed/15190030 (Diakses pada tanggal tanggal 2 Desember 2012).

2. WHO 2005. Containing antimicrobial resistance, WHO policy perspectives of medicine.

3. Karam G, Heffner JE. Emerging issues in antibiotic resistance in blood-borne infections. Am J Respir Crit Care Med 2000;162:1610-6.

4. Dellinger RP, Levy MM, Carlet JM, Bion J, Parker MM,dkk. Surviving sepsis campaign:international guidelines for management of severe sepsis and septic shock. Crit Care Med 2008;36:296-327.

5. Murthy R. Implementation of strategies to control antimicrobial resistance. Chest 2001;119:405s-11s.

6. Kollef MH, Ward S, Sherman G. Inadequate treatment of nosocomial infections is associated with certain empirical antibiotic choices. Crit Care Med 2000;28:3456-64.

7. Tambunan T. Kebijakan pengendalian resistensi antimikroba. Diunduh dari: http://cridtrophid.files.wordpress. com/2012/03/materi-workshop.pdf (Diakses tanggal 2 Desember 2012).

8. Gyssens IC, van den Broek PJ, Kullberg BJ, Hekster Y, van der Meer JMW. Optimizing antimicrobial therapy. A method for antimicrobial drug use evaluation. J Antimicrobial Chemother 1992;30:724-7.

9. Frank Shann. Pediatric Drug Doses. Royal children hospital. Publisher : collective p/L. 2011.

10. Booth R. Pediatric drug dosage adjustments in patients with renal impairment or on renal replacement therapy for use on the intensive care and renal units. Diunduh dari: http://www.nppg.scot.nhs.uk/PICU/Dose\% 20Adjustments\%20in\%20CVVH.pdf. (Diakses pada tanggal 2 Desember 2011).

11. Dosing adjustments in renal impairment. Diunduh dari: www.clinicalpharmacy.uscf.edulidmpladult_guide tanggal. (Diakses pada tanggal 2 Desember 2012).

12. Mehrotra R, De Gaudio R, Palazzo M. Antibiotic pharmacokinetic and pharmacodynamic considerations in critical illness. Intensive Care Med 2004;30:214556.

13. Verbeeck RK. Pharmacokinetics and dosage adjustment in patients with hepatic dysfunction. Eur J Clin Pharmacol 2008;64:1147-61.

14. Mehrotra R, De Gaudio R, Palazzo M. Antibiotic pharmacokinetics and pharmacodynamic considerations in critical illness. Intensive Care Med 2004;20:214556.

15. Panduan Pelayanan Medis RSCM 2012.

16. Formularium Rumah Sakit Umum Pusat Nasional Dr. Cipto Mangunkusumo, 2012.

17. Loho T. Peta Kuman RSCM Juli-Desember, 2011.

18. Raymoin DP, Pelletier SJ, Crabtree TD. Impact of a rotating empirical antibiotic schedule on infectious mortality in an intensive care unit. Crit Care Med 2001;29:1101-8. 